\title{
Pituitary Gland Macroadenoma
}

National Cancer Institute

\section{Source}

National Cancer Institute. Pituitary Gland Macroadenoma. NCI Thesaurus. Code C43542.

A pituitary gland adenoma with a diameter greater than $10 \mathrm{~mm}$. Clinical manifestations

include headache, visual field disturbances, pituitary insufficiency, and mild hyperprolactinemia. 